\title{
BMJ
}

\section{Influence of smoking cessation after diagnosis of early stage lung cancer on prognosis: systematic review of observational studies with meta-analysis}

\author{
A Parsons, research fellow, ${ }^{1}$ A Daley, senior lecturer, NIHR career scientist, ${ }^{2}$ R Begh, research associate, ${ }^{1}$ \\ P Aveyard, clinical reader, NIHR career scientist ${ }^{1}$
}

${ }^{1}$ UK Centre for Tobacco Control Studies, Primary Care Clinical

Sciences, University of

Birmingham, Edgbaston,

Birmingham B15 2TT

${ }^{2}$ Primary Care Clinical Sciences, University of Birmingham

Correspondence to: A Parsons a.c.parsons@bham.ac.uk

Cite this as: BMJ 2010;340:b5569 doi:10.1136/bmj.b5569

\section{ABSTRACT}

Objective To systematically review the evidence that smoking cessation after diagnosis of a primary lung tumour affects prognosis.

Design Systematic review with meta-analysis.

Data sources CINAHL (from 1981), Embase (from 1980), Medline (from 1966), Web of Science (from 1966), CENTRAL (from 1977) to December 2008, and reference lists of included studies.

Study selection Randomised controlled trials or observational longitudinal studies that measured the effect of quitting smoking after diagnosis of lung cancer on prognostic outcomes, regardless of stage at presentation or tumour histology, were included.

Data extraction Two researchers independently identified studies for inclusion and extracted data. Estimates were combined by using a random effects model, and the $\mathrm{I}^{2}$ statistic was used to examine heterogeneity. Life tables were used to model five year survival for early stage nonsmall cell lung cancer and limited stage small cell lung cancer, using death rates for continuing smokers and quitters obtained from this review.

Results In 9/10 included studies, most patients studied were diagnosed as having an early stage lung tumour. Continued smoking was associated with a significantly increased risk of all cause mortality (hazard ratio 2.94, $95 \%$ confidence interval 1.15 to 7.54 ) and recurrence $(1.86,1.01$ to 3.41$)$ in early stage non-small cell lung cancer and of all cause mortality $(1.86,1.33$ to 2.59$)$, development of a second primary tumour $(4.31,1.09$ to 16.98), and recurrence $(1.26,1.06$ to 1.50$)$ in limited stage small cell lung cancer. No study contained data on the effect of quitting smoking on cancer specific mortality or on development of a second primary tumour in nonsmall cell lung cancer. Life table modelling on the basis of these data estimated $33 \%$ five year survival in 65 year old patients with early stage non-small cell lung cancer who continued to smoke compared with $70 \%$ in those who quit smoking. In limited stage small cell lung cancer, an estimated $29 \%$ of continuing smokers would survive for five years compared with $63 \%$ of quitters on the basis of the data from this review.
Conclusions This review provides preliminary evidence that smoking cessation after diagnosis of early stage lung cancer improves prognostic outcomes. From life table modelling, the estimated number of deaths prevented is larger than would be expected from reduction of cardiorespiratory deaths after smoking cessation, so most of the mortality gain is likely to be due to reduced cancer progression. These findings indicate that offering smoking cessation treatment to patients presenting with early stage lung cancer may be beneficial.

\section{INTRODUCTION}

Worldwide, lung cancer is the most commonly diagnosed form of cancer. ${ }^{1}$ In the United Kingdom, its annual incidence is second only to that of breast cancer, accounting for around 39000 new cancer diagnoses annually. ${ }^{2}$ In countries that have seen a high prevalence of smoking, around $90 \%$ of diagnoses of lung cancer are attributable to cigarette smoking. ${ }^{3}$ The increased incidence from smoking is proportional to the length and intensity of smoking history. ${ }^{4}$ On average, a lifetime smoker has a 20-fold increase in the risk of developing lung cancer compared with a lifetime non-smoker. ${ }^{1}$ Lung cancer is more common in men than in women, closely following past patterns of smoking prevalence, and $80 \%$ of cases are diagnosed in people aged over $60 .^{2}$

Smoking cessation before diagnosis reduces the risk of developing a primary tumour of all major histological types of lung carcinoma; the greatest reduction is seen in small cell and squamous cell tumours. ${ }^{5}$ However, whether smoking cessation after diagnosis of a lung tumour can improve survival rates is less clear. The biological mechanisms by which toxins in tobacco smoke cause lung cancer are complex and still not completely understood, but carcinogens in tobacco smoke may not only act as genetic inducers but also act to promote progression of the disease. ${ }^{67}$ As well as potentially reducing the risk of cancer related morbidity and mortality, quitting smoking at diagnosis could reduce overall mortality, as smoking cessation reduces mortality from other diseases such as heart disease, stroke, and chronic obstructive airways disease. ${ }^{89}$ 


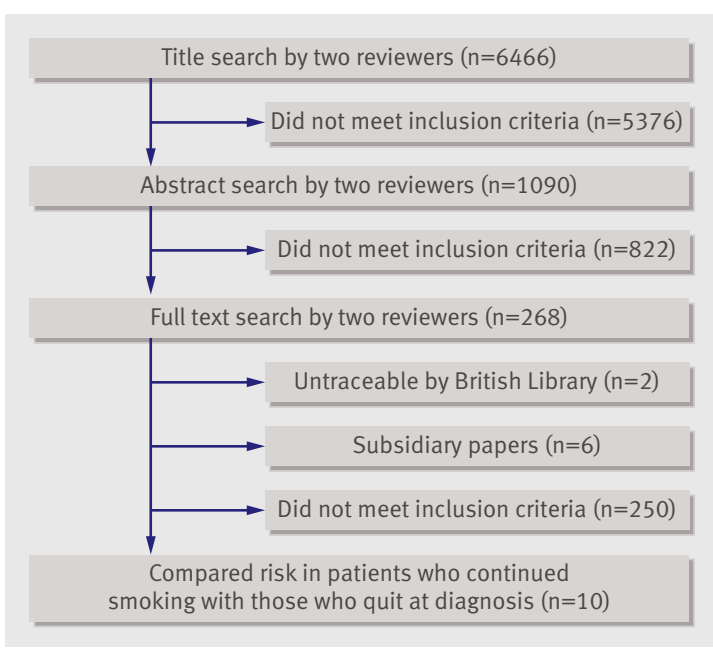

Fig 1| Flow of studies through trial

Prognosis of lung cancer is poor; around 7\% of patients survive for five years, and most patients are treated palliatively from diagnosis. The difficulty and discomfort of smoking cessation may mean that many patients with advanced disease choose to continue smoking. However, around 20\% of patients present early enough to be treated with curative intent (stage I-IIIa non-small cell lung cancer, limited stage small cell lung cancer) and have a relatively good prognosis. ${ }^{2}$ With improvements in treatment and screening and the ageing population, this group of patients is likely to grow..$^{10}$ The UK cancer reform strategy has called for improved services and support for survivors of cancer generally,,$^{11}$ and interventions to support smoking cessation after diagnosis tailored to the needs of lung cancer patients could be part of these. ${ }^{12}$ Such an intervention should be based on robust evidence that quitting smoking actually improves outcomes. We systematically reviewed the literature to summarise the evidence for the effect of quitting smoking after diagnosis of a primary lung tumour on prognostic outcomes.

\section{METHODS}

We searched for randomised controlled trials or longitudinal observational studies in patients with lung cancer, regardless of histology or stage at presentation, that measured the effect of quitting smoking after diagnosis on the risk of all cause mortality, cancer specific mortality, development of a second primary tumour, or recurrence. We searched CINAHL (from 1981), Embase (from 1980), Medline (from 1966), Web of Science (from 1966), and CENTRAL (from 1977) to December 2008, using search strategies developed with the support of an information specialist that included exploded $\mathrm{MeSH}$ terms and also text words relating to smoking and lung cancer. Because of the large volume of studies identified from the search, we separately used two types of filter for study design in databases that returned a high number of studies. Firstly, we filtered search returns for randomised controlled trials in Medline and Web of Science by using database specific filters. Secondly, we separately filtered search returns for longitudinal observational studies in Embase and Medline by using "prognosisspecificity" database specific filters and in Web of Science by using text words relating to the study design. All searches were combined in a reference manager database and duplicates removed. We also searched the reference lists of included studies.

Two independent reviewers read titles, abstracts, and full text papers and applied the inclusion criteria. Two reviewers independently extracted data from included full text papers. For each study, we extracted data on baseline characteristics (age, sex, histology, stage, grade, and smoking history) of the study population that could potentially confound the link between smoking and the outcome. We also extracted the number of continuing smokers, the number of quitters, and the length of follow-up. We extracted survival outcomes as hazard ratios with $95 \%$ confidence intervals. If these were not presented, we followed methods described by Parmar to extract them from KaplanMeier curves, $\mathrm{P}$ values, or percentage survival (for example, five year survival). ${ }^{13}$ We contacted authors if data were not presented in a useable form. In some studies, observed risk was presented as a proportion of expected risk calculated by Poisson regression modelling with general population data. In these cases, we calculated the hazard ratio by indirect comparison. ${ }^{14}$ We combined extracted hazard ratios by using a random effects inverse variance model in Stata. We compared adjusted and unadjusted estimates separately for each outcome in both non-small cell and small cell lung cancer, and we tested for statistical heterogeneity by using the $\mathrm{I}^{2}$ test. Papers in languages other than English were translated.

We assessed the quality of studies on the basis of a framework proposed by Altman for the assessment of prognostic studies. ${ }^{15}$ Two points were available for each of clarity of the inclusion criteria, controlling for comorbidities, method of obtaining smoking data (with an extra point for biochemical validation), clarity of definition of smoking category, and length of followup, with a maximum score of 11 .

Assuming that the findings of the review reflected a causal relation between smoking cessation and risk of all cause mortality, we further investigated the data by constructing life tables for a hypothetical group of 100 patients aged 65 years with early stage lung cancer to estimate how many deaths would be prevented by smoking cessation within the non-small cell lung cancer and small cell lung cancer populations during five years. We applied the average risk of death for continued smoking estimated from studies included in this review that reported survival curves to estimate the number of patients surviving after five years. ${ }^{1617} \mathrm{We}$ estimated five year survival in quitters at diagnosis by applying the death rate of continuing smokers multiplied by the reciprocal of the multivariate hazard ratio for all cause mortality presented in this review. 
One possible explanation for any improvements seen in the survival of patients who stop smoking might be a reduction in mortality from cardiorespiratory causes, as the risk of death from these diseases reduces after cessation. ${ }^{918}$ Consequently, we estimated the expected contribution of cardiovascular and respiratory diseases by using life tables as above to find the number of cardiorespiratory deaths prevented by smoking cessation in the general population. We estimated the risk of death due to cardiorespiratory causes in the general population of 65-69 year olds from data from the Office for National Statistics. ${ }^{19}$ We assumed that this death rate was approximately that of the non-smoking population, because around $12 \%$ of this age group smoke. ${ }^{20}$ We multiplied this rate by the relative risk of death from cardiorespiratory causes in lifelong smokers to estimate the number of deaths that would be expected over five years from cardiorespiratory causes in the general population of 65 year olds who smoke. We then applied the risk reduction from cessation to estimate the number of deaths that would be prevented and compared this with those prevented in non-small cell lung cancer and small cell lung cancer populations as estimated in this review. ${ }^{9}$

\section{RESULTS}

We did not identify any randomised controlled trials testing the effect of smoking cessation on prognostic outcomes in lung cancer. Also, in all studies identified except one,${ }^{21}$ most of the patients presented with early stage lung cancer and so the results reflect the possible effect of smoking cessation in early stage lung cancer only rather than in advanced disease. We obtained full text articles for 268 papers, from which we included 10 individual cohort studies in the review (fig 1).

\section{Characteristics of included studies}

A small proportion (10/268) of retrieved studies compared the risk of developing outcomes of interest in participants who continued smoking with that in people who quit smoking around the time of diagnosis. ${ }^{161721-28}$ Of these, five studies estimated the impact of continued smoking on all cause mortality (four non-small cell lung cancer, two small cell lung cancer), four studies looked at the development of second primaries (one non-small cell lung cancer, three small cell lung cancer), and two studies looked at recurrence of the primary tumour (one non-small cell lung cancer, one small cell lung cancer). No studies reported the impact of continued smoking on cancer specific mortality. In eight studies that reported sex, most participants were male, ranging from $55 \%$ to $86 \%$. All studies reported stage of disease; nine of the studies used a sample of patients of whom more than $75 \%$ presented in potential curable early stages - that is, stage 1-3a non-small cell lung cancer or limited stage small cell lung cancer. Only one study reported tumour grade (table 1). ${ }^{25}$

Overall, scores for quality of studies ranged from 5 to 9 points out of a maximum of 11 points. Most studies measured exposure to smoking retrospectively on the basis of self report, and definitions of smoking status were often not clear. Quality points were also lost owing to lack of adequate control for comorbidities. Patients were followed up for smoking status at six months or longer in five studies, ${ }^{1622232628}$ but smoking was only measured at the time of diagnosis or treatment in four studies, ${ }^{17212427}$ and follow-up was not defined in one study. ${ }^{25}$ Two studies defined quitting as continuous abstinence from within six months of starting treatment to longest follow-up, ${ }^{22} 23$ and one study defined quitting as continuous abstinence during and after treatment. ${ }^{21}$ The remaining studies did not give a definition of

\begin{tabular}{|c|c|c|c|c|c|c|c|c|c|}
\hline Author (year) & No in study* & $\begin{array}{c}\text { No of } \\
\text { continuous } \\
\text { smokers } \dagger\end{array}$ & $\begin{array}{c}\text { No of } \\
\text { quitters } †\end{array}$ & $\begin{array}{c}\text { Continuous } \\
\text { smokers (\%) } \ddagger\end{array}$ & Men (\%) & $\begin{array}{l}\text { Squamous cell } \\
\text { tumour (\%) }\end{array}$ & $\begin{array}{l}\text { Small cell lung } \\
\text { cancer (\%) }\end{array}$ & $\begin{array}{l}\text { Stage 1-3a/ } \\
\text { limited (\%) }\end{array}$ & Grade 1-2 (\%) \\
\hline \multicolumn{10}{|c|}{ Non-small cell lung cancer studies } \\
\hline Baser $(2006)^{16}$ & 93 & 47 & 46 & 51 & 49 & NR & 0 & 90 & NR \\
\hline Kawaguchi $(2006)^{22}$ & 62 & 16 & 19 & 46 & 81 & 48 & 0 & 100 & NR \\
\hline $\operatorname{Nia}(2005)^{17}$ & 311 & 169 & 35 & 83 & 86 & 47 & 0 & 92.1 & NR \\
\hline $\begin{array}{l}\text { Saito-Nakaya } \\
(2006)^{24}\end{array}$ & 238 & 6 & 92 & 6 & 60.9 & 21 & 0 & 81 & NR \\
\hline Shiba $(2000)^{25}$ & 156 & 8 & 61 & 12 & 72 & 59 & 0 & 100 & 72 \\
\hline \multicolumn{10}{|c|}{ Small cell lung cancer studies } \\
\hline $\begin{array}{l}\text { Johnston-Early } \\
(1980)^{21}\end{array}$ & 112 & 57 & 35 & 62 & NR & 0 & 100 & 29 & NR \\
\hline Kawahara $(1998)^{23}$ & 70 & 33 & 31 & 52 & 60 & 0 & 100 & 100 & NR \\
\hline Tucker $(1997)^{26}$ & 611 & 214 & 181 & 54 & 55 & 0 & 100 & 79 & NR \\
\hline Videtic $(2003)^{27}$ & 215 & 79 & 107 & 42 & 60 & 0 & 100 & 100 & NR \\
\hline Yoshida $(1996)^{28}$ & 61 & 26 & 33 & 44 & 80.3 & 0 & 100 & 85 & NR \\
\hline
\end{tabular}


quitting. In three studies, ${ }^{232628}$ patients were included in the analysis if they had survived two years disease free, and one study included only patients who had been disease free for three years (table 2). ${ }^{22}$

\section{Effect of quitting smoking at diagnosis on disease progression and mortality \\ Non-small cell lung cancer \\ Four studies reported estimates of the association} between continued smoking and all cause mortality, one study reported the association with occurrence of a second primary tumour, and one study with recurrence in non-small cell lung cancer (fig 2). Estimates were derived from samples in which at least $80 \%$ of patients were diagnosed with a stage 1-3a tumour. Unadjusted estimates suggested that continued smoking was associated with an increased risk of all cause mortality of $19 \%$ compared with quitters, although this was not significant. One of the four studies reported the association of baseline prognostic indicators with smoking status and showed no significant difference in distribution, suggesting limited confounding. ${ }^{17}$ However, adjustment for key prognostic variables resulted in an almost threefold increase in risk of all cause mortality for continuing smokers (hazard ratio 2.94, 95\% confidence interval 1.15 to 7.54 ). After adjustment, we found no significant increase in the occurrence of second primaries (hazard ratio 2.29, 0.50 to 10.58 ); however, one study reported an almost twofold increase in risk of recurrence for continuing smokers $(1.86,1.01$ to 3.41$)$.

\section{Small cell lung cancer}

All cause mortality in continued smokers with small cell lung cancer was significantly increased before and after adjustment, and adjustment strengthened the association (unadjusted hazard ratio $1.18,1.03$ to 1.36 ; adjusted hazard ratio $1.86,1.33$ to 2.59 ) (fig 3). Estimates were derived from populations in which at least 79\% of patients were diagnosed with limited stage disease, apart from one study in which $29 \%$ of patients presented with limited stage disease. We found no heterogeneity between unadjusted scores despite a marked difference between the populations in terms of stage at presentation (table 1). Unadjusted estimates suggested an $86 \%$ increase in risk of developing a second primary tumour, which was strengthened after adjustment to a fourfold increase in risk for continuing smokers over those who quit at diagnosis (hazard ratio 4.31, 1.09 to 16.98), although confidence intervals were wide. One study reported an unadjusted estimate for the association between continued smoking on recurrence that was statistically significant (hazard ratio 1.26, 1.06 to 1.50). Baseline characteristics for this study were presented by smoking group and were distributed equally apart from a significantly higher proportion of women in the group that continued smoking.

\section{Contribution of cardiovascular and respiratory mortality to reduced mortality}

The life table analysis was based on a notional cohort of 65 year old smokers diagnosed with early stage nonsmall cell lung cancer or limited stage small cell lung cancer. Assuming a causal relation between smoking cessation and all cause mortality, the estimated five year survival rates were $33 \%$ in continuing smokers and $70 \%$ in quitters for non-small cell lung cancer and $29 \%$ in continuing smokers and $63 \%$ in quitters for small cell lung cancer. In life table analyses based on data for the general population, five year survival from cardiorespiratory deaths was estimated at $93 \%$ in smokers and $95 \%$ in quitters.

\section{DISCUSSION}

We reviewed 10 observational studies, all of which showed some evidence that people who continue to

Table 2|Methodological characteristics of included studies and quality score

\begin{tabular}{|c|c|c|c|c|c|c|c|}
\hline Author (year) & $\begin{array}{l}\text { Prospective (1)/ } \\
\text { retrospective ( } 2 \text { ) }\end{array}$ & $\begin{array}{l}\text { Exposure follow- } \\
\text { up* (maximum) }\end{array}$ & $\begin{array}{l}\text { Method of outcome } \\
\text { measurement }\end{array}$ & $\begin{array}{l}\text { Outcome } \\
\text { follow-up* } \\
\text { (years) } \\
\text { (maximum) }\end{array}$ & $\begin{array}{l}\text { Outcomes } \\
\text { measured }\end{array}$ & Treatment $†$ & $\begin{array}{c}\text { Study } \\
\text { quality score }\end{array}$ \\
\hline \multicolumn{8}{|c|}{ Non-small cell lung cancer studies } \\
\hline Baser $(2006)^{16}$ & 1 & 1 year & Self report, case notes & $5+$ & $\mathrm{ACM}$ & Mixed & 9 \\
\hline Kawaguchi $(2006)^{22}$ & 2 & 3 years & Self report, questionnaire & 12.2 & SP & Mixed & 8 \\
\hline Nia $(2005)^{17}$ & 2 & Unclear & Self report, questionnaire & 11.25 & ACM, REC & Mixed & 7 \\
\hline Saito-Nakaya $(2006)^{24}$ & 1 & 1 month & Self report, case notes & 7.6 & $\mathrm{ACM}$ & Surgery & 7 \\
\hline Shiba $(2000)^{25}$ & 1 & Unclear & Self report, case notes & $5+$ & $\mathrm{ACM}$ & Surgery & 5 \\
\hline \multicolumn{8}{|c|}{ Small cell lung cancer studies } \\
\hline Johnston-Early $(1980)^{21}$ & Unclear & After treatment & Self report, verbal & 4 & $\mathrm{ACM}$ & Chemotherapy/radiotherapy & 6 \\
\hline Kawahara (1998) ${ }^{23}$ & 2 & 2 years & Self report, verbal† & $10+$ & SP & Chemotherapy/radiotherapy & 8 \\
\hline Tucker $(1997)^{26}$ & 2 & 2 years & Self report, case notes & $10+$ & SP & Chemotherapy/radiotherapy & 7 \\
\hline Videtic $(2003)^{27}$ & 2 & Start of treatment & Self report, case notes & 7 & ACM, REC & Chemotherapy/radiotherapy & 5 \\
\hline Yoshida $(1996)^{28}$ & 1 & 2 years & Self report, case notes/verbal† & $10+$ & SP & Chemotherapy/radiotherapy & 8 \\
\hline
\end{tabular}

$\mathrm{ACM}=$ all cause mortality; $\mathrm{REC}=$ recurrence; $\mathrm{SP}=$ second primary.

* Last point at which exposure data and outcome data were measured from beginning of study.

†Mixed=combination of surgery and chemotherapy/radiotherapy or both.

$\ddagger$ Questionnaire or verbal follow-up completed by patients still alive at time of maximum follow-up or by relatives. 
smoke after a diagnosis of early stage lung cancer have an associated higher risk of recurrence, second primary tumour, or all cause mortality compared with those who stop smoking at that time. Although unadjusted estimates suggest that the associated increase in risk of continuing (or the benefit of cessation) is modest at around $20 \%$, the adjusted estimates suggest a more than doubling of the risk of death from continued smoking. In both early stage non-small cell lung cancer and limited stage small cell lung cancer, we found evidence of a significant association between continued smoking and recurrence of the primary tumour; in limited stage small cell lung cancer, we found also evidence of a substantial elevation in the incidence of a second primary tumour. These elevated risks were apparent within seven years of diagnosis. In a life table model, assuming that these observations arose from a causal relation, we estimated the benefits of cessation to be substantial; the benefits on all cause mortality seem likely to be mainly due to reduced progression of cancer rather than prevention of cardiorespiratory disease, but no studies reported cancer specific death rates to confirm this.

\section{Strengths and limitations of study}

An important strength of this study is the exhaustive search for relevant studies. Five of the 10 studies were ostensibly about the relation of other potential prognostic variables to outcomes but happened to present data on smoking status as a potential confounder of those relations. Such a strategy mitigates concern about publication bias because the decision to publish was unrelated to the findings on smoking status and cancer outcome.

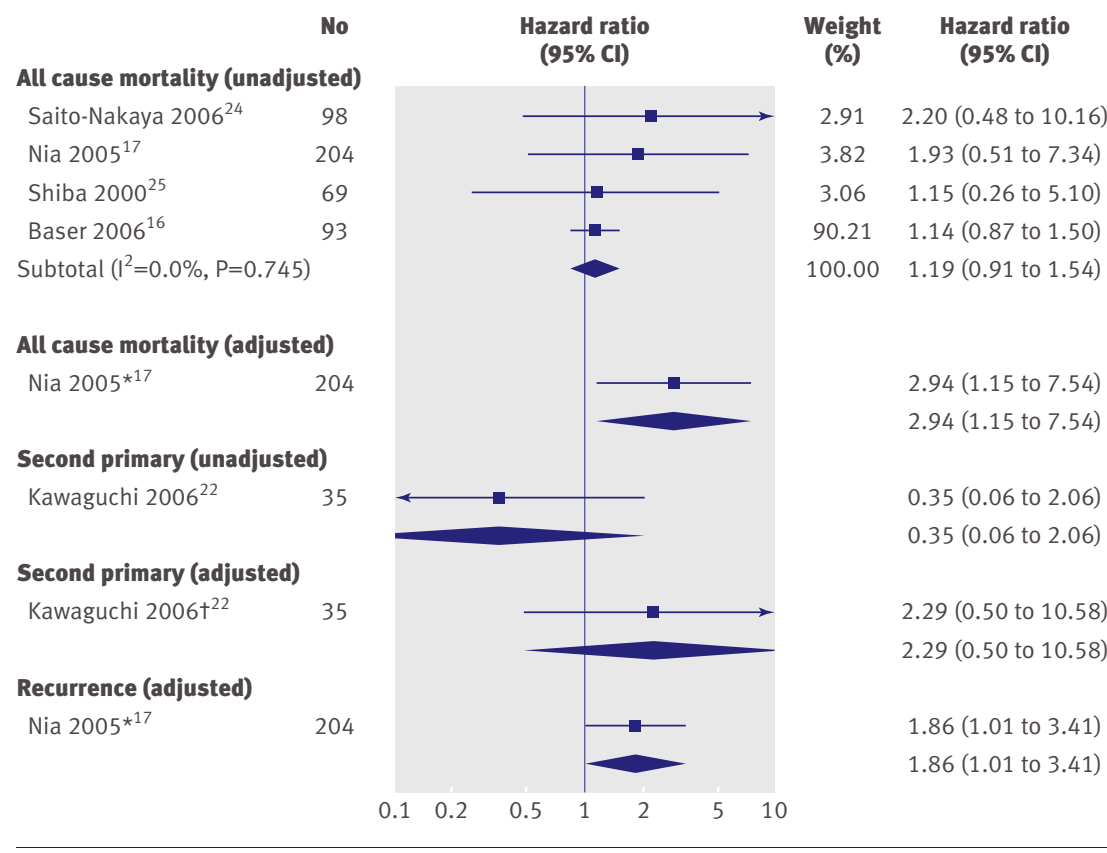

$\overline{\text { Fig } 2}$ | Effect of continued smoking on all cause mortality and recurrence in non-small cell lung cancer. Weights are from random effects analysis. *Adjusted for age, sex, type of operation, histology, postoperative radiotherapy, $\mathrm{N}$ status, $\mathrm{T}$ status, and previous malignancies.

†Adjusted for sex, histology, and cumulative smoking
We did this review to find evidence that smoking cessation improves prognostic outcomes in patients with lung cancer, but in the absence of data from randomised controlled trials no causal inferences can be made. This is the most important limitation of the study. Also, only one study reported on the association of smoking cessation and prognosis in a sample of patients presenting in mainly advanced disease, so the implication of these findings that smoking cessation is beneficial applies only to patients with early disease.

A major challenge with systematic reviews of observational studies is the possibility of uncontrolled confounding. Four of the 10 included studies presented data on the baseline distribution of potential confounders split by quitting status. ${ }^{16172127}$ Two studies found an uneven distribution of baseline factors ${ }^{1617}$; the group that stopped smoking contained a higher proportion of male patients in both studies and more patients with a history of cancer in one study. If, in general, potential confounding variables were not associated with quitting status, the ratio of unadjusted to adjusted hazard ratios within studies should be randomly distributed about one. For those studies that presented unadjusted and adjusted hazard ratios, these ratios were lower than one, and multivariate analysis showed a strengthened effect. ${ }^{172327}$ This suggests that smokers with unfavourable prognostic factors were the most likely to give up smoking, so that unadjusted estimates underestimated the benefits of quitting.

We assessed quality on the basis of criteria proposed by Altman, ${ }^{15}$ and we found studies to be of moderate quality with between $44 \%$ and $67 \%$ of the total available score. Definitions of smoking abstinence were generally poor, and only five of the 10 studies assigned patients to smoking categories on the basis of smoking status recorded at six months or more after diagnosis. Future studies in this area need to use accepted standards for measurement of smoking abstinence. ${ }^{29}$

\section{Comparison with previous studies}

No previously published systematic reviews have estimated the effect of smoking cessation on prognosis after a diagnosis of lung cancer. However, this question has been investigated for other cancers. A systematic review of observational studies suggested that smoking cessation after bladder cancer is beneficial, but owing to confounding and methodological concerns of included studies no firm conclusions could be drawn. ${ }^{30}$ Some observational studies have also shown an association between smoking cessation in patients with head and neck cancer and reduced risk of disease progression and mortality, but the absence of a systematic review and meta-analysis means that the strength of this association is uncertain. ${ }^{31-33}$

Our review also collected data on rates of postdiagnosis smoking cessation. Reports in the literature of the proportion of patients with lung cancer who continue to smoke after diagnosis are conflicting, with estimates ranging from $13 \%$ to $60 \% .^{34-36}$ Variation in reported rates may be due to differences in the clinical 


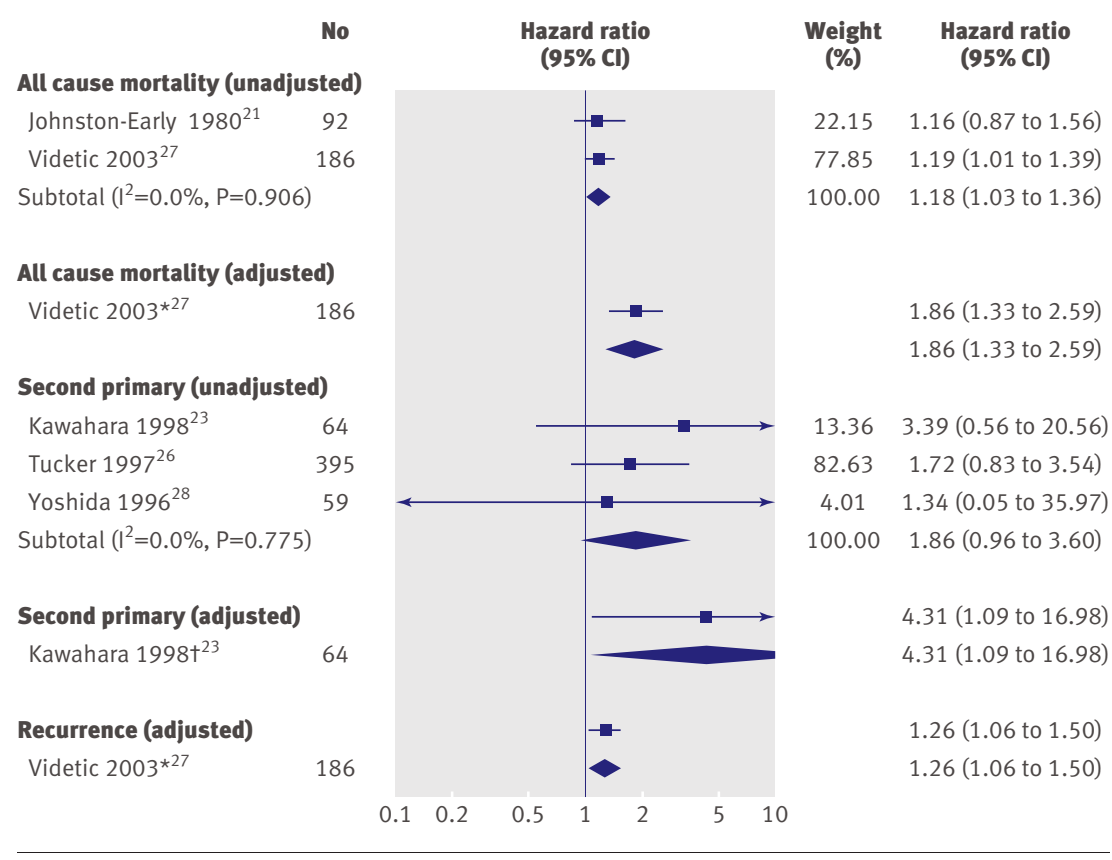

Fig 3 Effect of continued smoking on all cause mortality, development of a second primary, or recurrence in small cell lung cancer. Weights are from random effects analysis. *Adjusted for sex, age, and volume of limited disease. †Adjusted for sex, age, performance status, etoposide, radiotherapy, and cumulative smoking

characteristics of study populations, course of treatment, and methods of measuring smoking abstinence. ${ }^{37}$ In studies included in this review, the proportion of current smokers at diagnosis who continued to smoke ranged from $6 \%$ to $83 \%$. Reasons for this heterogeneity may be that some studies collected data on smoking status retrospectively, that no studies used biochemical confirmation, and that some studies measured only change in smoking status at the time of diagnosis or treatment without follow-up measurements. This may have mixed the true exposure status, which is likely to have underestimated the benefits of cessation as quitters are more likely to relapse. ${ }^{38}$

\section{Possible explanations for findings}

Assuming that the association between smoking cessation and risk of all cause mortality represents a causal relation and is not due to bias or confounding, at least two possible explanations exist. Firstly, smoking cessation may decrease the risk of death due to other smoking related causes such as cardiorespiratory diseases. Secondly, smoking cessation might decrease the risk of disease progression and death.

Life table modelling showed that the reduction in cardiorespiratory deaths that might be expected in the general population from smoking cessation increased five year survival by $2 \%$ in absolute terms, whereas smoking cessation after the diagnosis of early stage non-small cell lung cancer and limited stage small cell lung cancer increased five year survival by $37 \%$ and $34 \%$. This exercise was based on assumptions that are likely to underestimate the possible mortality benefit from smoking cessation. For the
65-69 year old general population, the baseline estimate of cardiorespiratory death rate was based on an assumption that the population were non-smokers; however, although the prevalence of smoking is only around $12 \%$, many will be ex-smokers, conferring a baseline risk greater than that of a completely non-smoking population, which would overestimate the reduction from cardiorespiratory causes. On the other hand, the higher prevalence of pre-existing cardiorespiratory disease in patients with lung cancer means that the absolute mortality gains seen in a general population are probably lower than those in lung cancer patients. ${ }^{39}$ Neither assumption seems sufficiently inaccurate to challenge the data suggesting that the major benefit from smoking cessation would be conferred by a reduction in cancer specific risk, if the reduced risk seen in this review was caused by smoking cessation.

The risk of cardiovascular related illness and death is known to decrease after smoking cessation in patients with coronary heart disease,${ }^{40}$ reducing dramatically over the first three years ${ }^{41}$ but reducing the risk of developing lung cancer after smoking cessation generally takes longer. ${ }^{941}$ This review has found evidence that after lung cancer has been diagnosed, reductions in risk of developing a second primary or recurrence were associated with quitting within seven years, suggesting that, even at this stage, the prognostic outlook can be improved by smoking cessation. Whether components of tobacco smoke affect the progression of lung cancer is currently not known, although a recent review suggests that tobacco derived carcinogens such as aromatic hydrocarbon compounds may induce cellular changes that progress the disease. ${ }^{7}$ Another possibility is that nicotine might have a role in angiogenesis and therefore promote tumour growth. ${ }^{43}$ The findings of our review support the hypothesis that continued smoking affects the behaviour of a lung tumour. Establishing the role of cigarette smoke in progression of cancer will not only produce the necessary evidence for implementing smoking cessation interventions but may also help to identify cellular mechanisms for therapeutic targeting.

\section{WHAT IS ALREADY KNOWN ON THIS TOPIC}

Smoking increases the risk of developing a primary lung cancer; lifelong smokers have a 20 -fold increased risk compared with non-smokers

Whether stopping smoking after a diagnosis of lung cancer improves outcomes is not known

\section{WHAT THIS STUDY ADDS}

For early stage lung cancers, smoking cessation is associated with a substantial reduction in the risk of death

Life table modelling indicates that most of the benefit from smoking cessation is due to a reduced likelihood of cancer progression rather than a reduction in cardiorespiratory deaths 


\section{Conclusion}

The UK cancer reform strategy has underlined the need for rehabilitative care of survivors of cancer to reduce the risk of disease progression and improve quality of life. ${ }^{11}$ These data provide a strong case that smoking cessation treatment for early stage lung cancer patients who have been unable to quit may have an important role in secondary prevention. Such a programme should be based on evidence that quitting smoking is causally related to improved outcomes and that smoking cessation interventions in this group are cost effective. This review provides sufficient evidence to support a randomised trial to examine these questions.

We thank Anne Fry-Smith, senior information specialist for the West Midlands Health Technology Appraisal Collaboration (WMHTAC) and the Aggressive Research Intelligence Facility (ARIF) at the University of Birmingham, for support in developing the search strategies, and Jon Deeks, professor of health statistics, and Roger Holder, senior lecturer in statistics, at the University of Birmingham for statistical support. Contributors: All authors identified studies for inclusion and extracted data. AP did the analysis and drafted the paper, which was edited by AD, $\mathrm{RB}$, and PA. AP is the guarantor.

Funding: The work was undertaken by the UK Centre for Tobacco Control Studies, a UKCRC Public Health Research centre of excellence. Funding came from the British Heart Foundation, Cancer Research UK, Economic and Social Research Council, Medical Research Council, and National Institute for Health Research, under the auspices of the UK Clinical Research Collaboration. PA and AD are supported by National Institute for Health Research career scientist fellowship awards. The views expressed in this publication are those of the authors and have not been influenced by the funding bodies.

Competing interests: PA has done consultancy work for the manufacturers of smoking cessation drugs. AP has been reimbursed by Pfizer for attending a conference.

Ethical approval: Not needed.

Data sharing: Technical appendix including the search strategies, Stata commands, and life table calculations available from the corresponding author.

1 Alberg AJ, Samet JM. Epidemiology of lung cancer. Chest 2003;123:21S.

2 Cancer Research UK. CancerStats. 2007. http://info. cancerresearchuk.org/cancerstats/.

3 Peto R. Mortality from smoking in developed countries 1950-2000: indirect estimates from national vital statistics. Oxford University Press, 1994.

4 Peto R. Influence of dose and duration of smoking on lung cancer rates. IARC Sci Publ 1986; 74:23-33.

5 Khuder SA, Mutgi AB. Effect of smoking cessation on major histologic types of lung cancer. Chest 2001;120:1577-83.

6 Hecht SS. Tobacco smoke carcinogens and lung cancer. J Natl Cancer Inst 1999;91:1194-210.

7 Yoshino I, Maehara Y. Impact of smoking status on the biological behavior of lung cancer. Surgery Today 2007;37:725-34.

8 International Agency for Research on Cancer. Reversal of risk after quitting smoking: IARC handbook of cancer prevention. International Agency for Research on Cancer, 2007.

9 Doll R, Peto R, Boreham J, Sutherland I. Mortality in relation to smoking: 50 years' observations on male British doctors. $B M$ J 2004;328:1519-28.

10 Sugimura H, Yang P. Long term survivorship in lung cancer. Chest 2006;129:1088-97.

11 Department of Health. Cancer reform strategy. Stationery Office, 2007 (available at www.dh.gov.uk/en/Publicationsandstatistics/ Publications/PublicationsPolicyAndGuidance/dh 081006).

12 Stull VB, Snyder DC, Demark-Wahnefried W. Lifestyle interventions in cancer survivors: designing programs that meet the needs of this vulnerable and growing population. J Nutr 2007;137:243-8S.

13 Parmar MKP, Torri V, Stewart L. Extracting summary statistics to perform meta-analysis of the published literature for survival endpoints. Stat Med 1998;17:2815-34.

14 Song F, Glenny AM, Altman DG. Indirect comparison in evaluating relative efficacy illustrated by antimicrobial prophylaxis in colorectal surgery. Control Clin Trials 2000;21:488-97.
15 Altman DG. Systematic reviews of evaluations of prognostic variables. BMJ 2001;323:224-8.

16 Baser S, Shannon VR, Eapen GA, Jimenez CA, Onn A, Lin E, et al. Smoking cessation after diagnosis of lung cancer is associated with a beneficial effect on performance status. Chest 2006;130:1784-90.

17 Nia PS, Weyler J, Colpaert C, Vermeulen P, Marck EV, Chil PV. Prognostic value of smoking status in operated non-small cell lung cancer. Lung Cancer 2005;47:351-9.

18 Kawachi I, Colditz GA, Stampfer MJ, Willett WC, Manson JE, Rosner B, et al. Smoking cessation and time course of decreased risks of coronary heart disease in middle-aged women. Arch Intern Med 1994:154:169-75.

19 UK National Statistics. Publication hub: gateway to UK national statistics. 2009 www.statistics.gov.uk/hub/index.html.

20 Taylor T, Lader D, Bryant A, Keyse L, Joloza MT. Smoking-related behaviour and attitudes, 2005. Office for National Statistics, 2006

21 Johnston-Early A, Cohen MH, Minna JD, Paxton LM, Fossieck BE Jr, Ihde DC, et al. Smoking abstinence and small cell lung cancer survival: an association. JAMA 1980;244:2175-9.

22 Kawaguchi T, Matsumura A, luchi K, Ishikawa S, Maeda H, Fukai S, et al. Second primary cancers in patients with stage III non-small cell lung cancer successfully treated with chemo-radiotherapy. Jpn / Clin Oncol 2006;36:7-11.

23 Kawahara M, Ushijima S, Kamimori T, Kodama N, Ogawara M, Matsui K, et al. Second primary tumors in more than 2 year diseasefree survivors of small cell lung cancer in Japan: the role of smoking cessation. Br/Cancer 1998;78:409-12.

24 Saito-Nakaya K, Nakaya N, Fujimori M, Akizuki N, Yoshikawa E, Kobayakawa M, et al. Marital status, social support and survival after curative resection in non-small-cell lung cancer. Cancer Sci 2006;97:206-13.

25 Shiba M, Kohno H, Kakizawa K, lizasa T, Otsuji M, Saitoh Y, et al. Ki67 immunostaining and other prognostic factors including tobacco smoking in patients with resected nonsmall cell lung carcinoma. Cancer 2000;89:1457-65.

26 Tucker MA, Murray N, Shaw EG, Ettinger DS, Mabry M, Huber MH, et al. Second primary cancers related to smoking and treatment of small-cell lung cancer. J Natl Cancer Inst 1997;89:1782-8.

27 Videtic GMM, Stitt LW, Dar AR, Kocha WI, Tomiak AT, Truong PT, et al. Continued cigarette smoking by patients receiving concurrent chemoradiotherapy for limited-stage small-cell lung cancer is associated with decreased survival. J Clin Oncol 2003;21:1544-9.

28 Yoshida T, Matsui K, Masuda N, Kasunoki Y, Takada M, Yana T, et al. Risk of second primary cancer in two-year survivors of small cell lung cancer. Japanese Journal of Thoracic Diseases 1996;34:741-6.

29 West R, Hajek P, Stead LF, Stapleton J. Outcome criteria in smoking cessation trials: proposal for a common standard. Addiction 2005;100:299-303.

30 Aveyard P, Adab P, Cheng KK, Wallace MA, Hey K, Murphy MFG. Does smoking status influence the prognosis of bladder cancer? A systematic review. BJU Int 2002;90:228-39.

31 Stevens MH, Gardner JW, Parkin JL, Johnson LP. Head and neck cancer survival and lifestyle change. Arch Otolaryngeal 1983;109:746-9.

32 Silverman S Jr, Gorsky M, Greenspan D. Tobacco usage in patients with head and neck carcinomas: a follow-up study on habit changes and second primary oral/oropharyngeal cancers. J Am Dent Assoc 1983;106:33-5.

33 Browman GP, Wong G, Hodson I, Sathya J, Russell R, McAlpine L, et al. Influence of cigarette-smoking on the efficacy of radiationtherapy in head and neck-cancer. N Engl J Med 1993;328:159-63.

34 Dresler CM, Bailey M, Roper CR, Patterson A, Cooper JD. Smoking cessation and lung cancer resection. Chest 1996;110:1199-202.

35 Gritz ER. Smoking behavior following diagnosis in patients with stage I non-small cell lung cancer. Cancer Causes Control 1991;2:105-12.

36 Pinto BM, Trunzo IJ. Health behaviors during and after a cancer diagnosis. Cancer 2005;104:2614-23S.

37 Cox LS, Sloan JA, Patten CA, Bonner JA, Geyer SM, McGinnis WL, et al. Smoking behavior of 226 patients with diagnosis of stage IIIA/IIIB non-small cell lung cancer. Psychooncology 2002;11:472-8.

38 Hughes JR, Keely J, Naud S. Shape of the relapse curve and long-term abstinence among untreated smokers. Addiction 2004;99:29-38.

39 Janssen-Heijnen M, Schipper RM, Razenberg P, Crommelin MA, Coebergh JW. Prevalence of co-morbidity in lung cancer patients and its relationship with treatment: a population-based study. Lung Cancer 1998;21:105-13.

40 Critchley JA, Capewell S. Mortality risk reduction associated with smoking cessation in patients with coronary heart disease. JAMA 2003;290:86-97.

41 Ockene JK, Kuller LH, Svendsen KH, Meilahn E. The relationship of smoking cessation to coronary heart disease and lung cancer in the Multiple Risk Factor Intervention Trial (MRFIT). Am J Public Health 1990;80:954-8

42 Heeschen C, Jang JJ, Weis M, Pathak A, Kaji S, Hu RS, et al. Nicotine stimulates angiogenesis and promotes tumour growth and atherosclerosis. Nat Med 2001;7:833-9.

43 Cooke JP. Angiogenesis and the role of the endothelial nicotinic acetylcholine receptor. Life Sci 2007;80:2347-51. 